\title{
Prostate-Specific Antigen: From Promising to Disappointment Tool for Diagnosis of Chronic Renal Failure in Predialysis Patients
}

\author{
Ali Abdul Hussein S. Al-Janabi ${ }^{1}$ \\ ${ }^{1}$ Department of Microbiology, College of Medicine, University of \\ Karbala, Karbala, Iraq
}

Asian J Oncol 2021;7:82-84.
Address for correspondence Ali Abdul Hussein S. Al-Janabi, PhD,
Department of Microbiology, College of Medicine,
University of Karbala, Karbala 00964, Iraq
(e-mail: aljanabi_bio@yahoo.com).

\begin{abstract}
Keywords

- PSA

- chronic kidney failure

- prostate

- renal dialysis

Introduction Prostate-specific antigen (PSA) is a biomarker commonly used for detection of prostate cancer. Its viability as a marker for diagnosis of chronic renal failure (CRF) in predialysis patients was investigated.

Methods Sera from 230 patients with CRF were analyzed by enzyme-linked immunosorbent assay (ELISA) for determining total PSA (tPSA) levels before hemodialysis.

Results Of the patients investigated, $98.69 \%$ had a normal PSA level with a value less than $4 \mathrm{ng} / \mathrm{mL}$. Three elderly men with both kidney failure showed a moderate elevation of PSA level.

Conclusion PSA is considered a nonsignificant indicator for diagnosis of CRF.
\end{abstract}

\section{Introduction}

Chronic kidney disease (CKD) is considered a severe type of urinary tract disease that is recognized by a spectrum of deficiency in kidney function with a decrease in glomerular filtration rate (GFR). ${ }^{1}$ Kidney failure is characteristic of end-stage renal disease (ESRD) or stage 5 of CKD. It is characterized by GFR decrease to less than $15 \mathrm{~mL} / \mathrm{min} / 1.73 \mathrm{~m}^{2}$ according to the classification of the American National Kidney Foundation-Kidney Disease Outcomes Quality Initiative (NKF-KDOQI). ${ }^{2}$ The common clinical features of ESRD include accumulation of toxins, concentrated urine, and electrolytes in the kidney with a deficiency in the ability to maintain fluid balance. $^{1}$

Prostate-specific antigen (PSA), a member of the tissue kallikrein family, is a glycoprotein antigen usually produced by the epithelial cells of the prostate gland. ${ }^{3}$ It is most commonly used as an indicator marker for detecting prostate cancer. ${ }^{4}$
In some cases, PSA levels can be higher in the presence of benign prostate cancer, ${ }^{4}$ which decreases its specificity for malignant disease detection. Although there is no relationship between benign prostate hypertrophy (BPH) and $\mathrm{CKD},{ }^{5}$ the enlarged size of the prostate during the development of a benign disease is usually associated with the production of lower urinary tract symptoms (LUTS) and urinary retention which leads to elevated PSA level. ${ }^{6}$ Urinary tract infection (UTI) in patients with benign prostate disease can also present effect on the value of PSA by increasing ${ }^{7}$ or decreasing ${ }^{8}$ its levels.

The correlation between PSA and different types of kidney failure in men without prostate disease is variable. Some studies found a positive relationship, ${ }^{9}$ while others revealed a negative result of this association..$^{10,11}$ Thus, the level of total PSA (tPSA) in patients with chronic renal failure (CRF) was measured to investigate its possible role as marker for CRF diagnosis in patients before undergoing hemodialysis.
DOI https://doi.org/ $10.1055 / \mathrm{s}-0041-1729346$ ISSN 2454-6798
@2021. Spring Hope Cancer Foundation \& Young Oncologist Group of Asia.

This is an open access article published by Thieme under the terms of the Creative Commons Attribution-NonDerivative-NonCommercial-License, permitting copying and reproduction so long as the original work is given appropriate credit. Contents may not be used for commercial purposes, or adapted, remixed, transformed or built upon. (https://creativecommons.org/licenses/by-nc-nd/4.0/).

Thieme Medical and Scientific Publishers Pvt. Ltd. A-12, 2nd Floor, Sector 2, Noida-201301 UP, India 


\section{Methods}

\section{Reagents}

A tPSA enzyme-linked immunosorbent assay (ELISA) kit was purchased from Human GesellschaftfurBiochemica and DiagnosticambH (Germany).

\section{Sample Collection}

The study design was submitted on June, 21, 2018, to the ethics committee of the College of Medicine of the University of Karbala, Iraq, and was approved under the number 2056. Serum samples were collected from 230 males suffering from chronic renal failure (CRF) in one or both kidneys admitted to the hemodialysis department of the AL Hussein General Teaching Hospital of Karbala province (Iraq) from June to August 2019. The age of involved males ranged from 35 to 70 years (mean $43 \pm 1.7$ years). Hemolytic and lipemic sera were eliminated from the collected samples.

\section{ELISA Assay}

Collected sera were analyzed by ELISA technique for determining tPSA levels. The assay depends on the high affinity of the biotin-streptavidin system. The absorbance of the final product was measured at $450 \mathrm{~nm}$ within 30 minutes by a BioTek ELx800 ELISA reader (Winooski, United States). The concentrations of testing samples were obtained by means of a calibration curve, which was established from the calibrators supplied with the kit. The usual normal value of PSA in healthy individuals is less than $4 \mathrm{ng} / \mathrm{mL}$.

\section{Statistical Analysis}

The "t"-test was used to analyze data. The minimum level of $p$ value was $<0.01$ which is considered a significant level.

\section{Results}

Serum of 230 patients with CRF was tested for tPSA level in their blood before hemodialysis. Out of these, 227 (98.69\%) presented normal levels of this antigen with values of less than $4 \mathrm{ng} / \mathrm{mL}$ (mean $2.3 \mathrm{ng} / \mathrm{mL}$ ). Patients with normal values were older than 40 years ( - Table 1 ). Three elderly males with a mean age of 61 years and with a CRF in both of their kidneys had a moderately higher level of tPSA, but with no significant differences from the patient's total number (-Table $\mathbf{1}$ ).

Table 1 Total PSA (tPSA) levels in patients with chronic renal failure (CRF)

\begin{tabular}{|l|l|l|}
\hline PSA level $(\mathrm{ng} / \mathrm{mL})$ & $\begin{array}{l}\text { Number of } \\
\text { patients (\%) }\end{array}$ & Age mean (y) \\
\hline$<4$ & $227(72.6)^{\mathrm{a}}$ & 41 \\
\hline $4-6$ & $2(0.8)$ & 61 \\
\hline $6-8$ & $1(0.4)$ & 61 \\
\hline Total number & 230 & \\
\hline
\end{tabular}

aSignificant differences between patient. Total number at $p<0.01$.

\section{Discussion}

PSA is generally used for prediction or diagnosis of prostate cancer. ${ }^{4}$ The specificity of this antigen is not always high for malignant disease due to $35 \%$ of patients presenting high PSA levels and no prostate cancer. ${ }^{4}$ However, many prostate diseases, including malignant and benign cancers can be responsible for increasing the PSA level. ${ }^{4}$ Among benign diseases, any inflammatory disease in the human body can increase the concentration of blood PSA. ${ }^{4}$ Thus, infectious diseases causing kidney inflammation are considered an important factor able to raise PSA level, especially when combined with benign prostate enlargement. ${ }^{7}$

The most important CRF clinical feature is the reduction of GFR to $10 \%$; when GFR reaches $5 \%$ of normal function, the kidney function was regarded as in failure stage. ${ }^{12}$ Hemodialysis is often the best treatment for patients with CRF. ${ }^{9,10}$ In patients who underwent hemodialysis, a high PSA level was usually associated with the presence of prostate diseases. ${ }^{11}$ Thus, in absence of prostate disease, hemodialysis could not solely induce elevation of the PSA level..$^{10,13}$ However, our patients were tested for PSA level before hemodialysis to avoid the possible effect of dialysis on PSA value. ${ }^{14}$ The present result confirmed that PSA did not have a significant correlation with kidney failure in the majority of our patients.

Generally, 8 to $9 \%$ of men in advanced age (50-70 years) usually have elevated levels of serum PSA as a result of benign prostate hypertrophy (BPH) presence. ${ }^{3}$ Thus, high levels of PSA in three elderly patients with chronic renal failure in two kidneys may result from BPH and not from CRF. However, some patients with CRF may have high PSA levels at the predialysis stage and not before or after hemodialysis. ${ }^{13}$

PSA usually occurs in two forms in blood-noncomplexed free PSA (fPSA) that has a molecular mass of $\sim 30 \mathrm{kDa}$ and a complex PSA (cPSA) that is bound with $\alpha$-1-antichymotrypsin. ${ }^{15}$ Therefore, total PSA (tPSA) represents the sum of fPSA and cPSA. ${ }^{16}$ However, the level of all forms of PSA is not often affected in patients with CRF or UTI. ${ }^{7,10}$ Many studies that try to find an association between PSA level and CRF prefer the use of TPSA as an indicator rather than other forms of PSA. ${ }^{17}$ The high molecular mass of tPSA makes it difficult to pass through glomerular filtration under normal conditions, unless in the presence of severe damage in kidney tissue. Whereas, fPSA has a low molecular mass, facilitating its fast elimination by kidney through glomerular filtration. ${ }^{17,18}$ Thus, it is considered useless for detecting CRF due to it is easy elevation even in the presence of slight and/or moderate renal dysfunction. ${ }^{18}$ In conclusion, PSA level evaluation was considered a nonsignificant indicator for CRF diagnosis.

\section{Note}

All of the involved patients were volunteers and signed a consent form.

\section{Conflict of Interest}

None declared. 


\section{References}

1 Göőz M. Benign prostate hyperplasia and chronic kidney disease. In: Leao R, Pereria BJ, Coelho H, eds. Chronic Kidney Disease. Rijeka, Croatia: Intech; 2012: 347-353. Accessed April 19, 2021 at www.intechopen.com.

2 National Kidney Foundation. K/DOQI clinical practice guidelines for chronic kidney disease: evaluation, classification, and stratification. Am J Kidney Dis 2002;39(2(Suppl 1) :S1-S266

3 Sturgeon CM, Diamandis EP. Laboratory medicine practice guideline: use of tumor markers in testicular, prostate, colorectal, breast, and ovarian cancers. The Am Association Clinical Chem 2009;3

4 Caplan A, Kratz A. Prostate-specific antigen and the early diagnosis of prostate cancer. Am J Clin Pathol 2002;117(Suppl):S104-S108

5 Rule AD, Jacobson DJ, Roberts RO, et al. The association between benign prostatic hyperplasia and chronic kidney disease in community-dwelling men. Kidney Int 2005;67(6):2376-2382

6 Collin SM, Metcalfe C, Donovan J, et al. Associations of lower urinary tract symptoms with prostate-specific antigen levels, and screen-detected localized and advanced prostate cancer: a case-control study nested within the UK population-based ProtecT (Prostate testing for cancer and Treatment) study. BJU Int 2008;102(10):1400-1406

7 Zackrisson B, Ulleryd P, Aus G, Lilja H, Sandberg T, Hugosson J. Evolution of free, complexed, and total serum prostate-specific antigen and their ratios during 1 year of follow-up of men with febrile urinary tract infection. Urology 2003;62(2):278-281

8 Ulleryd P, Zackrisson B, Aus G, Bergdahl S, Hugosson J, Sandberg T. Prostatic involvement in men with febrile urinary tract infection as measured by serum prostate-specific antigen and transrectal ultrasonography. BJU Int 1999;84(4):470-474
9 Bruun L, Björk T, Lilja H, Becker C, Gustafsson O, Christensson A. Percent-free prostate specific antigen is elevated in men on haemodialysis or peritoneal dialysis treatment. Nephrol Dial Transplant 2003;18(3):598-603

10 Wolff JM, Ting O, Borchers H, Rohde D, Jakse G. Serum levels of prostate specific antigen in men on hemodialysis. Anticancer Res 2000;20(6D):5191-5193

11 Sasagawa I, Nakada T, Hashimoto T, et al. Serum prostatic acid phosphatase, gamma-seminoprotein and prostatic specific antigen in hemodialysis patients. Urol Int 1992;48(2):181-183

12 Milner Q. Pathophysiology of chronic renal failure. $\mathrm{Br} J$ Anaesth 2003;3(5):130-133

13 Kabalin JN, Hornberger JC. Prostate-specific antigen is not excreted by human kidney or eliminated by routine hemodialysis. Urology 1991;37(4):308-310

14 Tzanakis I, Kazoulis S, Girousis N, et al. Prostate-specific antigen in hemodialysis patients and the influence of dialysis in its levels. Nephron 2002;90(2):230-233

15 Coppolino G, Bolignano D, Rivoli L, Mazza G, Presta P, Fuiano G. Tumour markers and kidney function: a systematic review. BioMed Res Int 2014;2014:647541

16 Wang MC, Valenzuela LA, Murphy GP, Chu TM. Purification of a human prostate specific antigen. Invest Urol 1979;17(2):159-163

17 Djavan B, Shariat S, Ghawidel K, et al. Impact of chronic dialysis on serum PSA, free PSA, and free/total PSA ratio: is prostate cancer detection compromised in patients receiving long-term dialysis? Urology 1999;53(6):1169-1174

18 Celik M, Yuksel UC, Yildirim E, Gokoglan Y. Factors that may affect the measurement of prostate specific antigen levels in patients with cardiovascular disease. Eur Rev Med Pharmacol Sci 2013;17(3):422-423 